Food Consumption in Relation to Habitat in Breeding Chickadees

Author(s): H. N. Kluyver

Source: The Auk, Vol. 78, No. 4 (Oct., 1961), pp. 532-550

Published by: University of California Press on behalf of the American Ornithologists' Union

Stable URL: http://www.jstor.org/stable/4082187

Accessed: 08/11/2013 04:14

Your use of the JSTOR archive indicates your acceptance of the Terms \& Conditions of Use, available at http://www.jstor.org/page/info/about/policies/terms.jsp

JSTOR is a not-for-profit service that helps scholars, researchers, and students discover, use, and build upon a wide range of content in a trusted digital archive. We use information technology and tools to increase productivity and facilitate new forms of scholarship. For more information about JSTOR, please contact support@jstor.org. 


\section{FOOD CONSUMPTION IN RELATION TO HABITAT IN BREEDING CHICKADEES}

\section{H. N. Kluyver}

IN 1959 Dr. W. H. Drury, Jr., Director of the Hatheway School of Conservation Education at Drumlin Farm, invited me to come to Massachusetts to carry out some ornithological investigations in behalf of the Massachusetts Audubon Society. The Black-capped Chickadee (Parus atricapillus) was chosen for this study because it is easy to watch and because it would be possible to compare its biology with that of European tits, which I have studied for many years (Kluyver, 1950, 1951, 1952, 1957 ; Kluyver and Tinbergen, 1953).

Both European deciduous and coniferous woods are inhabited by tits (Parus species), and each species has a typical habitat. One species, the Great Tit (Parus major), although mainly adapted to deciduous woods, will also inhabit pine woods, where insects suitable for its food (in spring mainly caterpillars, as these larvae are large enough for feeding nestlings) are relatively scarce. Moreover, in European pine woods the Great Tit meets serious food competition from other species of tits, whose methods of hunting insects are better adapted to pine-wood conditions. Pine wood is, therefore, a marginal habitat for this species, with reproduction being lower and mortality higher than in deciduous woods.

Because it is the only species of Parus in eastern Massachusetts, the Black-capped Chickadee does not meet with any competition from allied species and lives in both types of wood. Natural mixed woods probably are its favorite habitat, where it hunts insects in both broadleaved trees and pines. It nests, at least in Massachusetts, primarily in dead birches. From my European experience I expected deciduous woods to contain more preferred food insects (both species and individuals) than pine. The object of my study was to investigate if and to what extent some of the factors that control population densityespecially reproduction and nestling mortality-are influenced by the availability of caterpillars and other food resources. Moreover, I wanted to study details of nest building and breeding biology, as well as dispersal of adults and young in the postreproductive season.

\section{Area of Study and Nesting Accommodation}

My observations were made in the woods of Drumlin Farm, which includes nine hectares (22 acres) of pure pine woods [red pine (Pinus resinosa) and white pine (Pinus strobus)] and 22 hectares ( 55 acres) 
of mixed wood, the latter consisting of a mixture of pines, oaks, and birches (gray, yellow, and black), with some ashes, maples, and hickories. This mixed wood consists of a canopy of high trees as well as an understory of bushes and dense deciduous scrub with scattered pines. Pure deciduous wood (mainly oaks) of an area of about 0.6 hectares (1.5 acres) was to be found on only one place. On Drumlin Farm 77 boxes suitable for chickadees were available. In the course of the preceding winter Dr. Drury put up an additional 24 boxes in a nearby oak wood. He also filled all of the boxes with wood chips and peat dust in order to meet the instinctive drive of the chickadees to dig a hole in soft wood. On Drumlin Farm this arrangement proved to be successful, 25 boxes being occupied by chickadees. In the oak wood, however, none of the 24 boxes were accepted. The reason may have been that all dead trees have been removed on Drumlin Farm, and that natural nesting accommodations are scarce. In the oak wood, dead birches were common, and the chickadees, which probably were not less numerous in the latter wood than on Drumlin Farm, used the natural nesting sites, which they had to dig out themselves. None of the boxes were excavated, and this suggests that the birds did not "find" these boxes. Indeed, some nests were found in natural cavities. The latter broods, however, were not included in my study, as I feared I would disturb the nests by cutting into the walls of the holes. ${ }^{1}$ Moreover, the nests in the oak wood were rather remote, and it would have taken much time and energy to include them in a regular comparative study. Because one nest was situated in a small pure oak wood on Drumlin Farm (nest box 113), I decided to study this brood intensively, and to eliminate the broods in natural holes in the large oak wood. Later I regretted having done so, as the parents of box 113 were extremely shy birds and, moreover, took a large amount of the food for their nestlings not from oaks but from more distant white pines. This was one of the reasons why I could not wholly carry out my projected study.

All nest boxes were either made of birch logs or were standard boxes covered with birch bark in order to meet the supposed preference of chickadees to nest in birches. I think this arrangement has fostered their success on Drumlin Farm. Seventeen of 77 boxes on Drumlin Farm were made of cut lumber with a rectangular cavity of 55 to 70 $\mathrm{cm}^{2}$, and 60 were logs with a circular area of 25 to $32 \mathrm{~cm}^{2}$. Two (12 per cent) of the 17 rectangular boxes were occupied by chickadees; and

1 This fear may have been unfounded as I learned in the course of the season that chickadees tolerate much more interference at their nesting sites than most European tits do. 
21 (35 per cent) of the 60 logs. These figures may indicate a preference for a circular breeding hole, or preference for the round log rather than the square box. Moreover, the cavity of the square boxes appeared to be too large, which led to poorer breeding results in one of them. Two of the log cavities were widened when the chickadees cut out a part of the back wall of the $\log$ before nest building was started. This action does not indicate that the original cavities were too small, for the birds only removed a part of the wall above the bottom and did not widen the nesting cavity. I think this action was merely a consequence of the birds' instinctive drive to cut a hole in soft wood. The entrance of most of the logs measured 3 to $31 / 2 \mathrm{~cm}$, and the depth of the underlying cavity was 12 to $15 \mathrm{~cm}$. All of the chickadee boxes were checked once in seven to 12 days.

\section{Egg LAying}

The chickadees began egg laying in the last week of April, seven out of 20 pairs having begun before or on 28 April. At that time a laying pause set in, which $I$ attribute to a cold spell that began on 27 April and ended on 1 May. As a consequence of this, only two pairs started their brood between 28 April and 5 May. Four days after the cold spell had ended, a new group of broods was started. An analogous influence of a cold spell setting in after the start of the laying season is often observed in European tits, which also show a delayed reaction of some days. As in chickadees, the tits that had started before the cold spell did not interrupt their laying action, but laid an egg every day as usual.

Laying season closed with one second brood, the first egg of which was laid on 8 June.

During the laying period the female is on the nest at night. She usually lays one egg a day, early in the morning, before she leaves the nest for the first time. During this period she leaves the nest half an hour later than usual.

Twice I established an exception to the rule that an egg is laid every day early in the morning. The female of box 26 laid her first egg in the late afternoon or evening of 1 May, and her second egg the next morning. This exception might be connected with the general delay of laying as a consequence of the abovementioned cold spell.

The female of box 27 missed a day in laying. The box contained one egg on 10 May. The next day I observed the behavior of the pair in question in the early morning. At the usual time of 0504 the male started its pheebee song. In an unusual action the female now immediately left the box. Later I checked the box and found that no egg had been laid. The next morning the female again laid an egg. 


\section{Clutch Size}

Among 25 broods, one clutch contained eight eggs, 14 clutches had seven eggs, eight clutches had six eggs, and the size of two clutches remained unknown. Clutches of six eggs were laid all through the season; the two last clutches, which started in early June, also contained this number of eggs. Clutches of seven were not laid after mid-May. The only clutch of eight eggs started on 28 April, with laying continuing throughout the cold spell. This suggests that the cold weather, though delaying the start of clutches, did not decrease the size of the clutches that had started before the weather turned cold.

The mean clutch size was 7.0 for the period to 28 April ( 7 broods), 6.6 for the period between 1 May and 10 May (11 broods), and 6.4 for the later five broods.

Any influence of habitat (deciduous or pine wood) or winter feeding on start of breeding or size of clutch could not be established, though such an influence might exist.

\section{INCUBATION}

Because some Black-capped Chickadee males showed indications of a brood patch, I originally thought that the species might differ from European tits, where incubation is the exclusive duty of the female. I must agree with Odum, however, that there is no evidence that the male takes any part in incubation. I always found the female incubating, though the male regularly comes to the nest to feed the female, either inside or outside the hole.

Incubation period (number of days between laying of last egg and hatching of eggs) was usually 12-13 days, which is the normal period in song birds. In one case I observed a prolonged incubation period (15 days), which must have been due to the fact that the female was not able to incubate in the usual way. It had built a nest in a large, rectangular box (area of bottom, $70 \mathrm{~cm}^{2}$ ) so that her loosely built moss nest had little support. During incubation the nesting cup steadily enlarged, and the eggs landed on the horizontal wooden bottom of the box, where they lay more or less scattered most of the time. Three of the seven eggs did hatch, but only after two days longer than usual.

The rhythmic behavior of the female during incubation, involving periods on and off the eggs, was studied in one brood (box 106, second brood). Observations covered 30 hours and were spread over three days. The average lengths of the periods spent on the eggs on those three days were 23 minutes, 27 minutes, and 18 minutes, 
respectively. Variability of on-periods ranged from seven to 47 minutes; periods of more than 35 minutes were rare, however. The female is often called off the eggs by the male, who intends to feed her, sometimes in the nesting cavity, but sometimes outside.

Average time off the eggs amounted to eight, seven, and eight minutes on the three days of my study, with the extremes being two and 17 minutes. During these periods the female often begs for food from the male. He feeds her at intervals, and in the meantime she also feeds herself.

\section{Nesting Success}

In the breeding season of 1959 the boxes contained 25 broods, eight (32 per cent) of which failed completely. House Wrens were the main predators and pilfered the eggs of five broods ( 20 per cent). The nestlings of one brood died with rachitis; an unknown predator took the newly hatched young of another brood; and in one brood all of the young died, one after another, of an unknown cause. No broods were abandoned because of death of parents, nor as a consequence of my frequent interference. The latter was due much more, however, to the faithfulness with which parent chickadees take care of their broods than to my own cautiousness. The birds endure much more interference at their broods than do most European tits.

The 17 successful broods consisted of five completely successful broods, where all of the eggs resulted in young leaving the nest, and 12 partly successful. Successful nests had 113 eggs. Ninety-six of these hatched; and of these, 11 young died in the nest and 85 nestlings fledged. Thus 75 per cent of the eggs laid in successful nests, and 51 per cent of eggs laid in both successful and unsuccessful nests, resulted in fledged nestlings. Nestling mortality (12 per cent of eggs hatched) was consequently very low. It is much lower than the analogous figure in European Great Tits in pine wood, and about equal to that of this bird in its most suitable habitat, the oak wood. As the Drumlin Farm chickadees collected the bulk of their food in pines, they are obviously very well adapted to this habitat.

In two broods (boxes 209 and 214) rachitis caused the death of all, or a part of, the young. This illness shows itself in poor development of legs and wings, and flexibility of tarsi. Moreover, body weights fell behind those usual for young chickadees. Rachitis is known to cause the death of nestling European tits in sandy regions poor in lime. On Drumlin Farm rachitis was also found on a sandy place. In box 209 all of the seven young died between the 10th and 18th 
day after hatching. In box 214 nestlings showed a remarkable recovery and left the nest of June 16 at an age of 20 days, which is two to three days later than usual. One of these birds was observed in good health near box 23 on 27 July.

\section{GROWTH OF NeSTLings}

I paid special attention to growth of nestlings, since the principal problem of my investigation was the influence that food supply available to parents for their nestlings exerts on nesting success.

Fledging periods were observed accurately in 11 nests: two of 16 days, four of 18 days, three of 19 days, and two of 20 days.

Data on growth of nestlings are presented in Table 1. Nestlings weigh about one $g$ at hatching time, and weight increases regularly in the course of 12 days to $10-11 \mathrm{~g}$. After that age weights increase little, the average at 15 days being $11.3 \mathrm{~g}$, which is close to the weight of adults. The average of 16 adult chickadees weighed at Drumlin Farm in May 1959 by Carl Helms was $12.2 \mathrm{~g}$ (extremes 11.0 and $14.1 \mathrm{~g})$.

No significant weight differences of nestlings could be found in

TABLE 1

Growth of Nestling Chickadees, Drumlin Farm, 1959

(Averages of weights in $\mathrm{g}$ )

\begin{tabular}{|c|c|c|c|c|c|c|c|c|c|c|c|c|c|}
\hline \multirow[t]{4}{*}{ Age } & \multicolumn{4}{|c|}{$\begin{array}{l}\text { First brood } \\
\text { Number of nestlings }\end{array}$} & \multirow[b]{2}{*}{$6 n$} & \multirow[b]{2}{*}{$7 n$} & \multirow[b]{2}{*}{$7 n$} & \multirow{4}{*}{$\underset{\text { broods }}{\text { All }}$} & \multicolumn{5}{|c|}{$\begin{array}{l}\text { Second brood } \\
\text { Number of nestlings }\end{array}$} \\
\hline & $3 n$ & $3 n$ & $5 n$ & $6 n$ & & & & & $3 n$ & $5 n$ & $5 n$ & $5 n$ & All \\
\hline & $\stackrel{\imath}{\sim}$ & $\hat{\approx}$ & $\approx$ & & $\stackrel{2}{\sim}$ & $\approx$ & $\stackrel{2}{2}$ & & $\stackrel{2}{2}$ & $\underset{\sim}{\sim}$ & $\underset{\sim}{*}$ & $\underset{\sim}{*}$ & \\
\hline & ڤ్ర & ڤ్ & ڤ̊ & 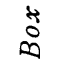 & ڤ్ & ڤొ & ఉ. & & ڤ్ & ڤ్ & in & \$ొ & \\
\hline 0 & & & & & & & & & 0.9 & & & & 0.9 \\
\hline 1 & & & 1.4 & & & & 22 & 1.4 & 17 & & 1.8 & 26 & 1.8 \\
\hline 3 & & & 3.3 & & & & & 3.3 & & 3.6 & 3.2 & & 3.4 \\
\hline $\begin{array}{l}4 \\
5\end{array}$ & & & 5.4 & & & & 5.6 & 5.5 & 3.7 & 5.6 & 5.0 & 3.8 & $\begin{array}{l}3.1 \\
4.8\end{array}$ \\
\hline $\begin{array}{l}6 \\
7\end{array}$ & 7.1 & 7.0 & 6.9 & & 6.9 & & 7.4 & $\begin{array}{l}7.0 \\
7.2\end{array}$ & 6.6 & 7.9 & 7.4 & 5.8 & $\begin{array}{l}5.8 \\
7.3\end{array}$ \\
\hline 8 & & & & 8.6 & & & & 8.6 & 8.2 & & & 7.6 & 67.9 \\
\hline 9 & & & 8.8 & & 10.2 & & 8.9 & 9.3 & & 9.7 & & & 9.7 \\
\hline 10 & & 9.8 & & & & 9.1 & & $\begin{array}{r}9.5 \\
10 ?\end{array}$ & & & & & \\
\hline $\begin{array}{l}11 \\
12\end{array}$ & 10.7 & & 10.2 & & 115 & & 9.6 & $\begin{array}{l}10.2 \\
11.5\end{array}$ & & & & $3.3_{9.0}$ & $\begin{array}{l}8.3 \\
9.0\end{array}$ \\
\hline 13 & & & 11.0 & & & 10.2 & 10.2 & 10.5 & & 10.4 & & & 10.4 \\
\hline $\begin{array}{l}14 \\
15\end{array}$ & & & & 11.1 & & & 11.3 & $\begin{array}{l}11.1 \\
11.3\end{array}$ & & & & & \\
\hline
\end{tabular}


early and late broods, nor between broods situated in deciduous (box 113) and pine wood (box 105).

\section{Kinds And Weights of Prey}

For studying I made use of three methods, each of which, however, was barely successful. Nevertheless, they provided an insight in the kind of prey that the parents collected. The methods consisted of: (1) Observations with binoculars. Larger prey, such as large caterpillars, sometimes can be recognized; smaller prey, however, hardly ever. (2) Observations from a blind. This method yields more success, but very often parents fly so rapidly into the box that no prey can be recognized. (3) Taking samples by closing the esophagus of nestlings with a metal collar gave little success, as most nestlings wearing such a collar refused to beg for food. The few samples collected were weighed, however, and gave a reliable basis for the estimation of weights of prey observed from the blind.

I recognized 65 prey items which, in a superficial way, can be classified as follows : 35 caterpillars (13 large and 22 small), 11 spiders, 6 small unidentified larvae, 4 small red larvae, 6 termites, 1 white butterfly or moth, 1 pupa, 1 fly.

Weights of these items may be estimated as follows: large, green caterpillars averaged at the end of May and in early June $200 \mathrm{mg}$ and at the end of June $300 \mathrm{mg}$; smaller caterpillars, $120 \mathrm{mg}$; spiders, $70 \mathrm{mg}$; 6 termites all together that were fed in one parcel, $50 \mathrm{mg}$.

Because caterpillars were, on the average, three times as heavy as the average of all other prey, the bulk of nestling food doubtless consisted of the former insect larvae.

Average weight of feedings turned out to differ considerably in different broods.

In nest box 16 (orchard) I estimated average weight of prey items as $70 \mathrm{mg}$. This very low average might be due to the early season of this brood, which was the first to hatch.

In boxes 105 and 106 (first and second brood of the same pair in pine wood) many big, green caterpillars were fed. Average weight of food items may be estimated at $120 \mathrm{mg}$ in the former and $180 \mathrm{mg}$ in the latter brood.

In box 204 (late brood in pines) prey items were small, average of 35 preys being estimated at $90 \mathrm{mg}$. The small average prey size of this brood was the more remarkable as big caterpillars were by no means scarce in close vicinity of this nest, as was shown by an incidental sample of caterpillar droppings.

Tinbergen (1960) showed that European tits often develop a specialization for hunting in a certain microhabitat and adhere tenaciously to it, even when other microhabitats in the meantime have developed better food resources. It might be that we have to seek along this line to find the explanation of why the parents of box 204 did not collect many green caterpillars. 
Number of Feedings and Duration of Activity

The number of times the parents entered the nest box (which is practically equal to the number of feedings, as parents rarely enter without bringing food) was mechanically recorded with two chronographs (see Figure 1 for contact apparatus) in five broods.

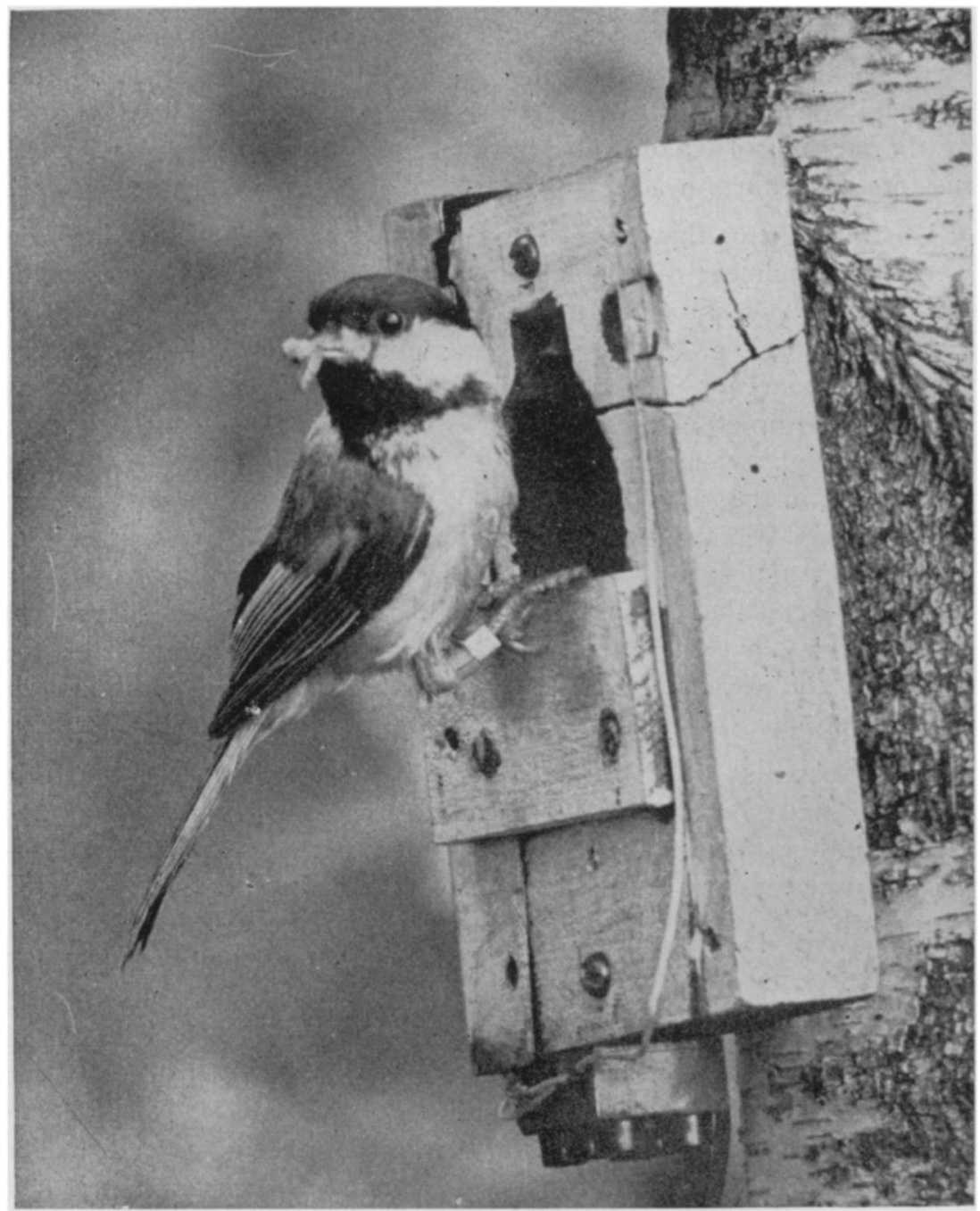

Figure 1. Chickadee with food for nestlings at nest box with contact apparatus. Entering parent moves hanging strip and makes chronograph operate. 
In order to study the influence of different habitats and different brood sizes on feeding activity, I calculated the daily number of feedings per nestling present in every box. Table 2 clearly shows large differences in number of feedings per nestling in different broods. The presence of many fellow nestlings, however, does not appear to exert any influence on the number of feedings that every nestling gets in a day. A nestling in a brood of five young (box 113) does not get more feedings than a congener in a brood of six. Even in a brood of three nestlings, the daily number of feedings per nestling does not exceed those of larger broods. This suggests that the need of food by the nestlings (demonstrated by the intensity of begging) regulates the rate of feedings by the parents.

Most prey items that were brought by the pair of box 16 (orchard) were small; number of feedings, on the other hand, turned out to be very large in this brood. In the brood of box 105 (pine wood) the number of feedings per nestling was much smaller, but prey size considerably larger. The same holds for the brood in box 106, which was a second brood of the same pair. This pair mainly collected large, green caterpillars for their nestlings. Number of feedings per nestling in box 204, in the same season as 106 , was much higher. The average prey size of 204, however, might hardly amount to half of that of 106 . These observations, together with the facts in the preceding paragraph, strongly suggest that the number of feedings per nestling is independent of brood size, but shows close correlation to the average size of the prey that the parents collect. Obviously, the need of nestlings for food usually does not reach a level that the parents are unable to meet.

If the parents usually do not work at the utmost level of their ability, it must be possible for them to accelerate their feeding pace in case nestlings have become hungry after a space of fasting. This indeed turned out to be possible in box 204 on two days (29 and 30 June), when we were taking a series of photographs. Preparations for taking these pictures interfered with the regular course of parental feedings, and on both days feedings were nearly stopped for several hours in the morning. From 1500 to 2000, however, the parents accelerated their pace to 118 on 29 June and 86 on 30 June. In the preceding days this pace had amounted to 47 only. Moreover, on each of the days on which pictures were made the parents ended their activity half an hour later than usual. And they even started it half an hour earlier than usual each day following a picture day, thus having a short night's rest. This extending of working hours proves that parents usually do not work as long as possible. In addition, it sug- 


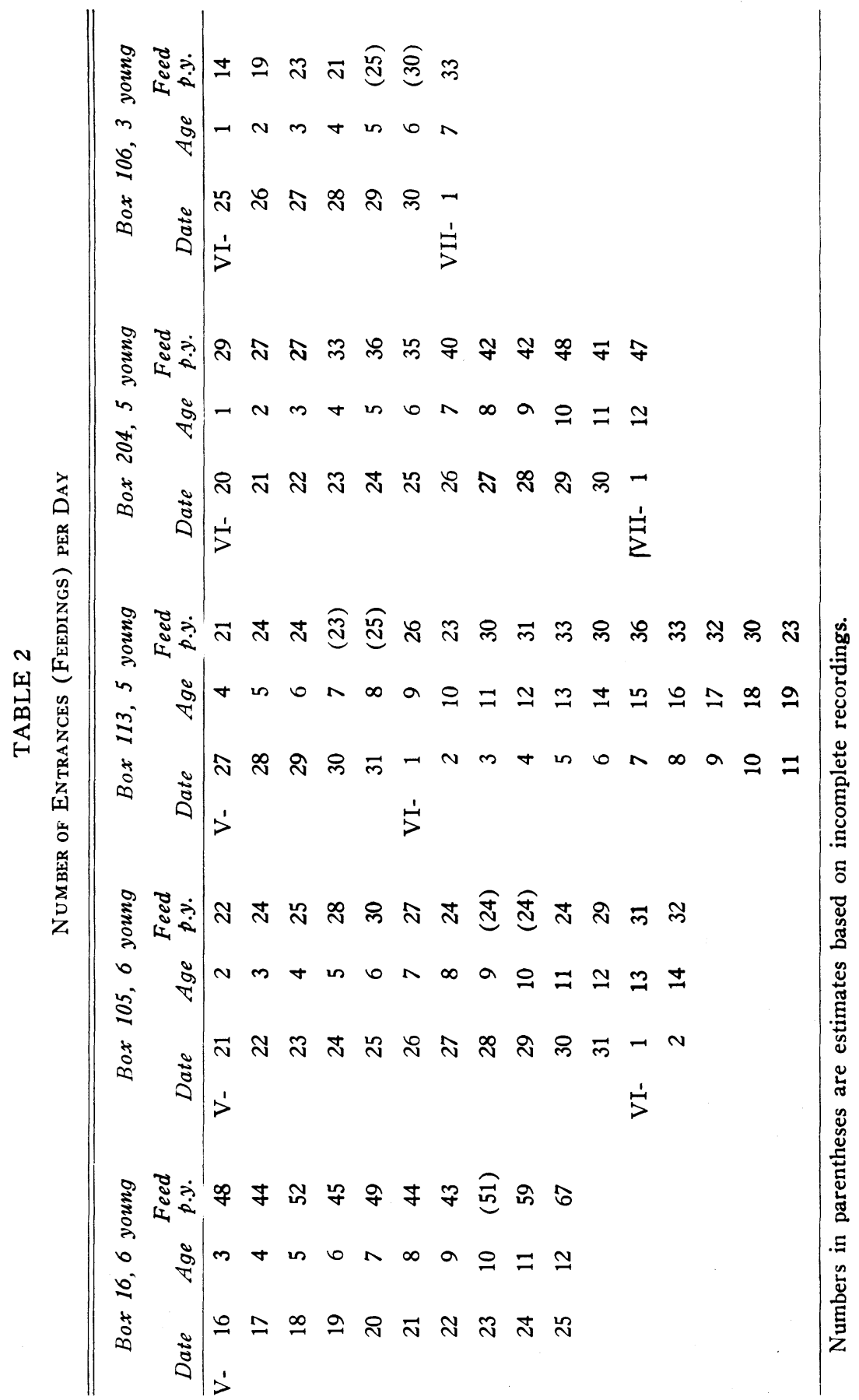


gests that they might have worked at top capacity in the afternoons of the days pictures were taken.

Daily number of feedings usually increases later in the nestling period, thus meeting the increasing need of food of the growing young. In European tits I have often seen the same trend.

Table 3 shows that in box 106 the incubating female arose very late (average of 86 minutes after sunrise) and retired very early (60 minutes before sunset). During the nestling period, when feeding the nestlings is the parents' main duty, the beginning of daily activity is much earlier and the end much later in all broods. Nevertheless, feeding activity usually does not start before sunrise, and in most of the broods starts some 10-20 minutes later than that. This is considerably later than the usual start of the male's song in the prenesting period, which again shows that the birds do not need the whole of their day for their feeding duty.

The parents cease feeding from five to 20 minutes before sunset. The female now ends all of her activity as she broods the nestlings

\section{TABLE 3}

Average and Extremes (in Minutes) of Beginning of Parental Activity AFTER SUNRISE AND ENd OF IT BEFORE SUNSET

\begin{tabular}{|c|c|c|}
\hline Box Stage Season & Beginning after sunrise & End before sunset \\
\hline 16 nestl. $15-25$ May & -1 (extr. 8 aft. and 21 & 22 (extr. 44 bef. and 1 \\
\hline 105 nestl. 21 May-3 June & $14 \begin{array}{l}\text { (extr. } 29 \text { aft. and } 6 \\
\text { bef.) }\end{array}$ & $\begin{array}{c}7 \text { (extr. } 27 \text { bef. and } 29 \\
\text { aft.) }\end{array}$ \\
\hline 113 nestl. 27 May-11 June & 6 (extr. 13 aft. and 7 & $\begin{array}{l}5 \text { (extr. } 42 \text { bef. and } 22 \\
\text { aft.) }\end{array}$ \\
\hline 106 incub. 16-24 June & $\begin{array}{l}86 \text { (extr. } 102 \text { aft and } 66 \\
\text { aft.) }\end{array}$ & $\begin{array}{l}60 \text { (extr. } 77 \text { bef. and } 49 \\
\text { bef.) }\end{array}$ \\
\hline 106 nestl. 25 June- 2 July & 18 (extr. 26 aft. and 8 & 28 (extr. 38 bef. and 7 \\
\hline 204 nestl. 19 June-1 July & $\begin{array}{l}23 \text { (extr. } 41 \text { aft. and } 4 \\
\text { aft.) }\end{array}$ & $\begin{array}{l}25 \text { (extr. } 49 \text { bef. and } 21 \\
\text { aft.) }\end{array}$ \\
\hline
\end{tabular}

at night. The male, however, remains active for some time. The end of feeding activity may depend not only upon the need of the nestlings for food, but also upon weather conditions. Sometimes a heavy rain shower caused an early end to the activity of the parents.

\section{Habitat Preference of Chickadees and Numbers of Insects}

Our observations showed that caterpillars [larvae of butterflies and moths (Lepidoptera) and sawflies (Tenthredinidae)] were the main items of prey fed to nestlings and fledglings. 
I tried to determine the relative abundance of caterpillars by comparing the numbers of fecal pellets dropped from the canopy and caught on horizontal screens with those samples from other areas. Caterpillar pellets are of a characteristic shape and very resistant to weather. They do not disintegrate in the rain, nor when dried. Screens were put up on 20 May, viz.: five screens under red pine, five screens under oak, two screens under ash, and, from 1 July onward, two screens under white pine. Pellets were collected each week in paper sacs, and dried. After removing coarse dirt, such as conifer needles, etc., the whole sample was weighed. Then we counted the number of pellets in a part of the sample. The total number of pellets per screen was approximately calculated in this way.

Our screens were $50 \times 50 \mathrm{~cm}$ each. One might wonder if the numbers of pellets that drop onto from two to five screens of this dimension have to be considered as a random sample for a section of woods. Do we not need a greater number of screens? The answer to this question depends on the uniformity of dispersion of the caterpillars in the wood. This uniformity can be established by studying the variability in the numbers of pellets found in the various screens. On Drumlin Farm I did not study this question in detail, but Tinbergen (1960) had done so in his extensive study of the dynamics of insect and bird populations in Dutch pine woods. I only established the fact that the numbers of droppings that I caught in the screens in a certain wood area did not vary a great deal. For this reason I have the impression that the averages give a fairly good comparative measure for pellet fall in the whole area.

Table 4 shows that pellet fall was subject to great variability in the course of the season of my study. In both pines and oaks pellet fall was high in late May and early June. After that it decreased, and then increased again in early July. It decreased again in mid-July. In red pines it reached a maximum in the last 10 days of July. In oaks, however, it steadily increased between mid-July and mid-August.

Pellet fall might be influenced by feeding activity as well as by the simple presence of caterpillars. Generally, activity of insects is primarily influenced by air temperature. A detailed study of the influence of temperature on pellet fall requires a study of the caterpillar species that produced the pellets. In general, it must be possible to identify a caterpillar and its instar by examination of its pellets. I had to give up this identification as my knowledge of American insect species is insufficient, and I confined my studies to a determination of the total number of pellets. 
Table 4 shows that in two periods in June and August, when temperature was low, pellet fall in red pines and oaks was also low. The same holds with ash trees. The drop in red pines and oaks in midJuly, however, was doubtless not caused by a fall of temperature; and in oaks the upward trend of pellet fall in August continued during a temperature drop. Thus, these observations do not show a clear correlation between pellet fall and air temperature.

Pellet fall must be primarily connected with numbers of caterpillars. The fluctuations of pellet fall in red pines and oaks (cf. Table 4) must be primarily due to the numbers of various caterpillar species, which followed one another in attacking the needles and leaves in the course of the season. Sizes and rates of growth of these various caterpillars, and consequently their pellet productions, are unequal. Nevertheless, in my opinion, pellet fall gives a fairly good, though crude, comparative measure of the numbers of caterpillars in various kinds of trees.

Do the numbers of falling pellets give us a good relative measure of the amount of food available for the chickadees in the trees concerned?

In the discussion of "Kinds of Weights of Prey" it was shown that nestling chickadees on Drumlin Farm were mainly fed with caterpillars. Chickadees show a clear preference for larger food items, especially with respect to the prey that they feed their young. In feeding nestlings, most pairs rarely make use of food items of less than $8 \mathrm{~mm}$. Therefore, they are not interested in the first instars of most caterpillars, and I did not count pellets smal!er than $1 \mathrm{~mm}$.

\section{TABLE 4}

Average Number of Fecal Pellets of Caterpillars Found per Day in Ground Screens of 2500 CM. ${ }^{2}$ Under Several Trees

(Air temperatures are calculated from mean daily air temperatures at Drumlin Farm B station)

\begin{tabular}{lccccrc}
\hline \hline Period & $\begin{array}{c}\text { Mean air } \\
\text { temp. F. }\end{array}$ & Red pine & White pine & Oak & Ash & $\begin{array}{c}\text { Ratio } \\
\text { oak/red pine }\end{array}$ \\
\hline 20-27 May & 62 & 14 & - & 33 & 10 & 2.4 \\
28 May-8 June & 62 & 87 & - & 64 & 21 & 0.7 \\
9-12 June & 65 & 64 & - & 28 & 8 & 0.4 \\
13-22 June & 56 & 36 & - & 9 & 3 & 0.2 \\
23 June-1 July & 64 & 40 & - & 15 & 10 & 0.4 \\
2-9 July & 65 & 75 & 472 & 30 & 38 & 0.4 \\
10-17 July & 68 & 35 & 141 & 17 & 100 & 0.5 \\
18-24 July & 72 & 69 & 48 & 25 & 82 & 0.3 \\
25 July-1 Aug. & 70 & 122 & 81 & 39 & 144 & 0.3 \\
2-8 Aug. & 62 & 56 & 52 & 56 & 61 & 1.0 \\
9-16 Aug. & 71 & 60 & 136 & 72 & 67 & 1.2 \\
\hline
\end{tabular}


In addition to caterpillars, other arthropods, such as spiders, which do not produce measurable numbers of fecal pellets, were important food. Moreover, chickadees doubtless do not take the same toll of all caterpillar species. Well-camouflaged caterpillars run less risk of being eaten than do more conspicuous ones.

In spite of these objections it seemed useful to investigate the correlation between the places of high pellet fall with those where chickadees were found feeding.

On the basis of my study of pellet fall, caterpillars were more numerous at the end of May in oaks than in red pines; but from early June to the end of July they were less numerous in the oaks (see Table 4). In the first half of August they were nearly as numerous in both habitats. In May caterpillars were less numerous in ash trees than in oaks, but in July their numbers increased considerably and for some weeks even surpassed those in oaks and red pines.

I expected that it would be easy to compare these observations of abundance of food with those in places where the chickadees collected food for nestlings. Establishment of the latter places, however, turned out to be more difficult than I expected. I often lost the feeding parents from sight as soon as they left their nest. As they were silent during the nestling period, it was usually impossible to find them again in the canopy. If a box is placed at the border of two types of vegetation, it may be that the direction that the leaving birds take suggests the preferred habitat. In two such cases the birds chose mainly red and white pines. The parents of box 16, which was situated in an orchard, did not collect any food in the fruit trees around their nesting site. This might be due to the fact that the trees were regularly sprayed with insecticides and contained hardly any caterpillars. The parents mainly flew to a nearby small red pine wood. In back of these woods, however, was an unsprayed orchard, and sometimes the birds extended their food excursions there. In box 113 the situation was the same. This box was situated in a small, deciduous wood, with a white pine wood on one side. But I rarely succeeded in establishing whether food was collected in the deciduous or in the pine wood.

Localization of the place of collection of food is much easier shortly after the fledglings have left the nest. The families wander through the woods and make themselves conspicuous by the call notes of the parents, and the begging notes of the young. A tenacious observer often sees the parents picking up prey and bringing it to their young.

After the family parties have disintegrated, adults and juveniles mingle in mixed flocks. I observed these "summer flocks" (which might be identical with "winter flocks") from mid-July onward. These flocks were less noisy than the family parties, but nevertheless they are easy to locate by the faint "seep" contact notes that the birds incessantly utter. 
My observations indicate that family parties and summer flocks concentrated in groves of trees, where caterpillars proved to be abundant. From 3 June onward, i.e., the very first date at which young left the nest site, the families had a marked preference for certain parts of the sanctuary-clumps of red and white pines. If on their journeys the birds passed oak woods, they did not avoid them, but rarely stayed longer than from five to 10 minutes (exceptionally 20 minutes). In pines, however, they often stayed several hours. Until the end of June the families almost exclusively stayed in red pines, which coincided with the abundance of caterpillars in the latter trees as compared with oaks (see Table 4). From the first of July onward the chickadees switched over to the white pines. As I had no screens under white pines, I placed them the next day. Indeed pellet fall showed that caterpillars were extremely abundant, though the bulk of them must have been small in size. Their numbers rapidly decreased. Around 20 July pellet fall under white pines had gone down below the level of that under red pines. Indeed, the chickadees changed over to the latter trees at about this time.

Two screens were under ash. Pellet fall under ash trees was rather low until July but considerably increased during this month and remained rather high until mid-August. I couldn't observe, however, any concentration of chickadees in ash trees during this time, probably because ash trees are scarce and scattered on Drumlin Farm.

These observations show that after the breeding season chickadees assemble and collect food in places where food is most abundant. (Analogous behavior is well known from winter time, when food is scarcer than in summer and concentration on places rich in food, so-called feeding tables, is much more evident.)

I failed to find any influence of the amount of food present in the habitat on the reproductive functions of the chickadees. For such an investigation various kinds of vegetation proved to be too much intermingled on Drumlin Farm, parcels of pines being in succession with oaks, birches, ash, and other trees. The planned observations in a nearly pure deciduous wood of oaks and birches had to be cancelled as the birds did not occupy the boxes in that wood.

\section{Population Trends}

During the breeding season I put my best efforts into trapping all of the breeding birds, especially in the periods when they were feeding nestlings. Twenty-five broods in the boxes were undertaken by 45 different parents. One pair undertook a second brood, another pair 
started a repeat brood in the same box where its former brood had been shortly disrupted by a House Wren, and one female undertook a repeat brood in a nearby box with change of male.

The 45 different birds present consisted of 14 that had been banded before (for the most part in fall and winter) on Drumlin Farm, 25 that were unbanded, and six of unknown banding status. I never observed the latter birds, either because their broods were disturbed in an early state or because one individual bird was very shy. Of the 25 unbanded breeding birds, 21 were trapped and banded, the brood was disturbed before I could trap two of them, and two were too shy to be trapped. All of the three shy birds must have been males.

As soon as the young become independent, family parties disintegrate. Many of the adults leave their spring territories, and all of the young leave the places where they were hatched. Now flocks of from five to 10 birds are formed. These flocks consist of both adults and young. I feel certain that very few or no young stayed in the immediate vicinity of their birthplaces. After the parents stopped feeding their young, i.e., from 10 to 25 days after the latter had left the nest, I did not observe any of the 80 color-banded young close to their birthplaces, and only four at a greater distance. Many young must have left Drumlin Farm shortly after they became independent. The large number of unbanded young that appeared on Drumlin Farm in July and August ( 80 per cent of the 245 observations that I made closely were unbanded) is also evidence of the quick separation and movement of the young. Some adults stay at their breeding places, but they also temporarily join the flocks that wander through their ranges. Family groups, as Odum rightly points out, do not form the basis of the flock. Flocking develops rapidly during July, and before the end of this month true "winter flocks," accompanied by a Whitebreasted Nuthatch (Sitta carolinensis) and a Downy Woodpecker (Dendrocopos pubescens), are often seen.

Observations in July and August suggest that many adults enlarge their range shortly after the breeding season. Many parents, among which were those wearing plastic collars, and which surely could not have escaped my attention, were no longer observed after they had stopped feeding their young. As I cannot believe that all of these birds died immediately thereafter, they must have enlarged their ranges outside my area of study.

A study of the recoveries that I gathered from bandings undertaken by the Drumlin Farm staff in preceding years (1956-1958) shows a remarkable difference in recovery percentages for different years. Of 
36 birds trapped for the first time and banded in the fall of 1956, nine specimens (25 per cent) were recaptured as breeding birds in 1959. Because two and one-half years had passed and because annual mortality is doubtless very high in the chickadee (in European tits it amounts to 50 per cent per annum in adult birds), this high percentage supports the assumption that the 1956 fall birds must have been, to a great extent, permanent residents.

In the fall of 1957 , chickadees were very abundant, and 52 specimens were trapped for the first time and banded. I succeeded in recapturing only two ( 4 per cent), although the time span between banding and recovery was a year shorter than in the 1956 bandings. Consequently, a higher percentage of the 1957 than of the 1956 fall birds must have either died (if residential) or emigrated.

It is difficult to understand why the 1957 death rate would be so much higher than the rate for the still-present 1956 birds. The most probable cause of this difference in per cent of home recoveries is that many of the 1957 birds did not stay on Drumlin Farm but rapidly wandered off.

Of 17 chickadees banded in the fall of 1958, I recaptured seven specimens. Considering the fact that these birds were subject to mortality for only half a year, it might be presumed that their rate of residents was between those of 1956 and 1957.

It would undoubtedly be worthwhile to continue this banding investigation.

Poor (1946) and, more recently, Lawrence (1958) have directed attention to the phenomenon that chickadees, after being residential for several years, are sometimes suddenly struck with a drive that urges them to wander. Such eruptive movements were observed in the fall and winter of 1941-1942 (Poor, 1948) and 1951-1952 (Lawrence, 1958). At those periods chickadees appeared in unusual habitats. Many of the birds appearing at several places in the United States in such years must have immigrated from more northern regions, whereas home birds emigrated elsewhere. In Lawrence's study the latter phenomenon was shown by a sharp drop in home recoveries of wintering birds, after this number had been fairly stable for some years.

Such eruptive movements are well known in other northern birds and also occur in European tits at irregular intervals (Cramp, et al., 1960). The bulk of these emigrated birds never return to their original places. Such movements probably occur after an unusually large production of young during the preceding breeding season or 
after unusually cold and cloudy summers. In both cases an acute food shortage might cause the phenomenon.

\section{ACKNOWLEDGMENTS}

My thanks are due to the Massachusetts Audubon Society for the fellowship that made my visit to the United States possible, and the Academy of Sciences of the Netherlands for allowing me to leave my duties in Holland for the time of my visit.

I thank the staff of the Hatheway School of Conservation Education, and especially Dr. W. H. Drury and his wife for their cordiality toward me and my family.

Miss I. LeMon and Mr. P. Ourusoff kindly helped me in field work, and the latter took the photograph used in Figure 1.

\section{SUMMARY}

This paper deals with a four-month study of the ecology of the Blackcapped Chickadee in the woods of Drumlin Farm, South Lincoln, Massachusetts.

Twenty-five of 77 nestlogs were occupied by chickadees, boxes having been made especially suitable for these birds by filling them with wood chips and peat dust, thus meeting their instinctive drive of digging a hole in soft wood.

The shortest distance between two chickadee nests was 55 meters.

Among 25 broods, one clutch contained eight eggs; 14, seven eggs; eight clutches, six eggs; and the size of two clutches remained unknown. Average of clutch size decreased as the breeding season progressed.

Rhythmic behavior of the female during incubation was studied during three days; averages of periods on the eggs amounting to 18-27 minutes, of periods off the eggs to seven to eight minutes. The male feeds his incubating female at intervals.

Of 25 broods, eight failed completely, the eggs of five of them being pilfered by House Wrens.

The nestlings of one brood died of rachitis.

Seventeen successful broods had 113 eggs, 96 of which hatched, 11 young died in the nest and 85 nestlings fledged.

Nestlings weighed about one $g$ at hatching. Weights increased regularly in the course of 12 days to $10-11 \mathrm{~g}$. After that weights increased only slightly. Nestlings fledged at 16-20 days.

Caterpillars were the main food of nestlings, with spiders second in importance. The former weighed $120-300 \mathrm{mg}$ each; the latter, about $70 \mathrm{mg}$ each.

Numbers of feedings were $21-29$ per day per young in the first days 
after hatching and increased to 30-36 per day. In an early nest, where young were fed with small prey, numbers of feedings were considerably higher.

In feeding nestlings, parents usually do not work at the utmost capacity.

Relative abundance of caterpillars in various types of wood was measured by pellet fall.

Chickadees prefer to collect food where it can be easily obtained.

Parents stop feeding their young 10-25 days after the latter have left the nest.

Immediately after juveniles become independent, family parties disintegrate and juveniles spread over a large area.

In July and August many adults stay at their breeding places, but enlarge their ranges.

A study of my 1959 recoveries of chickadees banded on Drumlin Farm in preceding years showed a high recovery percentage (25 per cent) of 1956 bandings, and a very low one (4 per cent) of 1957 bandings.

\section{Literature Cited}

Cramp, S., A. Pettet, and J. T. R. Sharrock. 1960. The irruption of tits in autumn 1957. Brit. Birds, 53: 49-77, 99-117, 176-192.

Kluyver, H. N. 1950. Daily routines of the Great Tit, Parus m. major L. Ardea, 38: 99-135.

KluYver, H. N. 1951. The population ecology of the Great Tit, Parus m. major L. Ardea, 39: 1-135.

KluYver, H. N. 1952. Notes on body weight and time of breeding in the Great Tit, Parus m. major L. Ardea, 40: 123-141.

KLuYver, H. N. 1957. Roosting habits, sexual dominance and survival in the Great Tit. Cold Spring Harbor Symposia of Quantitative Biology, XXII: 281-285.

Kluyver, H. N., and L. Tinbergen. 1953. Territority and the regulation of density in titmice. Arch. Neer. de Zool., 10: 265-289.

$\rightarrow$ LAWRence, L. D. K. 1958. On regional movements and body weight of Blackcapped Chickadees in winter. Auk, 75 : $415-443$.

$\rightarrow$ Odum, E. P. 1941. Annual cycle of the Black-capped Chickadee. Auk, 58: 314-333, 518-535.

$\rightarrow$ Odum, E. P. 1942. Annual cycle of the Black-capped Chickadee. Auk, 59: 499-531.

Poor, H. H. 1946. The Chickadee flight of 1941-42. Proc. Linn. Soc. New York, 54-57: 16-27.

Tinbergen, L. 1960. The dynamics of insect and bird populations in pine woods. Arch. Neer. de Zool., 13 : 265-336.

Instituut voor Oecologisch Onderzoek, Kemperbergerweg 11, Arnhem, Netherlands. Contribution Number 33 from the Hatheway School of Conservation, South Lincoln, Massachusetts. 